\title{
Membrane Applications in the Dairy Industry
}

\author{
Carolina E. Demaman Oro ${ }^{1(\mathbb{D})}$, Maicon S. N. dos $\operatorname{Santos}^{2}{ }^{\mathbb{C}}$, Rogério M. Dallago ${ }^{1(\mathbb{D})}$, \\ Marcus V. Tres 2,*(i) \\ 1 Department of Food Engineering, URI Erechim, Brazil; carolinae.oro@ hotmail.com (C.E.D.O.); dallago@uricer.edu.br \\ (R.M.D.); \\ 2 Laboratory of Agroindustrial Processes Engineering (LAPE), Federal University of Santa Maria, Brazil; \\ maiconsergions@gmail.com (M.S.N.S.); marcus.tres@ufsm.br_(M.V.T.); \\ * Correspondence: marcus.tres@ufsm.br (M.V.T).
}

Scopus Author ID 23096241300

Received: 28.07.2021; Revised: 10.09.2021; Accepted: 15.09.2021; Published: 17.10.2021

\begin{abstract}
The membrane separation process is a promising technique to be employed in the dairy industry. It can be used to treat effluents and for the recovery of molecules of interest to add value to product formulations. The study aspired to present the potential industrial use of membranes for dairy industries. Detailed research for scientific articles on the subject was conducted from the Scopus ${ }^{\circledR}$ scientific database, and the use of wastewater treatment in the dairy industry has increased significantly over the years. The findings presented are expected to provide a valuable theoretical framework for producers and industries related to milk production and whose objective is to optimize production performance and expressive benefits from an economic and environmental viewpoint. Moreover, membrane-based wastewater treatment has low energy demand, high volume recovery, significant water quality, multiple applications of purified water, eco-friendly performance, and favorable future perspectives.
\end{abstract}

Keywords: effluent; milk; recovery; wastewater treatment; vallue-added products.

(C) 2021 by the authors. This article is an open-access article distributed under the terms and conditions of the Creative Commons Attribution (CC BY) license (https://creativecommons.org/licenses/by/4.0/).

\section{Introduction}

The dairy industry is one of the largest and most successful sectors of the agricultural economy. The industrial process for producing dairy milk and dairy milk products involves the manufacture of pure milk and dried milk, as well as cheese, ice cream, protein concentrates and isolates, yogurts, and butter [1]. According to the Food and Agriculture Organization of the United Nations (FAO), milk production in 2020 exceeded 906 million tons and has indicated a promising scenario [2]. Nevertheless, statistical projections report a significant demand in some countries, mainly emerging markets with a high population advance in the coming years [3].

This panorama is extremely alarming since the amount of wastewater is 2.5 times higher than the processed milk, considering volume units [4]. The high concentration of organic and inorganic elements, biological oxygen demand (BOD), and chemical oxygen demand (COD) are prevailing characteristics of this type of effluent [5-8]. Also, dairy effluents are extremely harmful since there are high concentrations of compounds rich in organic matter and microorganisms [9]. This situation characterizes the current requirement to adopt processes that aim to increase productivity to meet the growing demand, which does not result in serious economic and environmental impacts. Accordingly, to overcome the expressive consequences and severe environmental and human risks caused by the inadequate disposition of dairy 
effluents in the environment, the implementation of strategies to improve the optimization of the milk production process and advance the performance of effluent treatment and obtaining high-quality water for reuse is widely appropriated $[9,10]$.

Using aerobic filters, biofilms, and anaerobic processes, the bio-based treatment showed promising conclusions [4, 9]. Nevertheless, applying this type of treatment requires many process steps, which limits its use and causes high costs and process time [4]. Thus, other categories of treatments have been explored over the years. The chemical and physicochemical approaches, by applying the electrocoagulation process (EC) and the addition of natural coagulants/flocculants, respectively, significantly facilitate the segregation and elimination of particles in the wastewater [11]. Nonetheless, the particular use of a range of inorganic coagulants presents high risks to the environment and human health [12]. This obstacle emerged on alternative treatments that improve the water quality present in industrial dairy effluents and are beneficial from an environmental and economic perspective. Correspondingly, prominent techniques have been scientifically reported, such as membranebased processes.

A considerable number of studies involving membrane-based processes applied to industrial dairy effluents are noticeable. Membrane filtration presented encouraging results and was based on high-level performance to obtain high-quality water for recycling $[13,14]$. The limitation status of membranes is directly related to the particularities of the product, such as the type of material, thickness, working pressure, permeate flux capacity, etc. [15]. Polymeric membranes are the most adapted for wastewater treatment, and the most common polymeric membranes are microfiltration (MF), ultrafiltration (UF), nanofiltration (NF), and reverse osmosis (RO) [16]. Therefore, the use of membranes has been intensified due to several advantages, such as the facility of the process, the high quality of the reused product, and economic benefits [12]. Based on a more restrictive scenario regarding the use of water originating from industrial effluents, the escalation in the application of membrane-based processes emerges as an ingenious alternative for future prospects [17].

The favorable background is identified in particular membranes applied in agroindustries and the integration of membranes for additional treatments. The association of MF and NF with physicochemical methods decreased 96\% COD and 99\% turbidity and color, proving to be a treatment that promotes water for reuse [12]. Furthermore, integrated MF and $\mathrm{RO}$ and MF and NF systems reduced $100 \%$ turbidity and up to $96 \%$ color [17]. Consequently, the use of membranes can optimize the wastewater management of dairy industries and enhance the recovery of purified effluents.

Additionally, it is interesting to verify the intensification of the scientific production scenario regarding the application of the dairy industry wastewater and the use of membranes to treat effluents. Transparent research for scientific articles published in the last 5 years was carried out from the Scopus ${ }^{\circledR}$ database considering the following keywords: dairy/wastewater/treatment (Figure 1 (a)) and dairy/wastewater/treatment/membrane (Figure 1 (b)). 

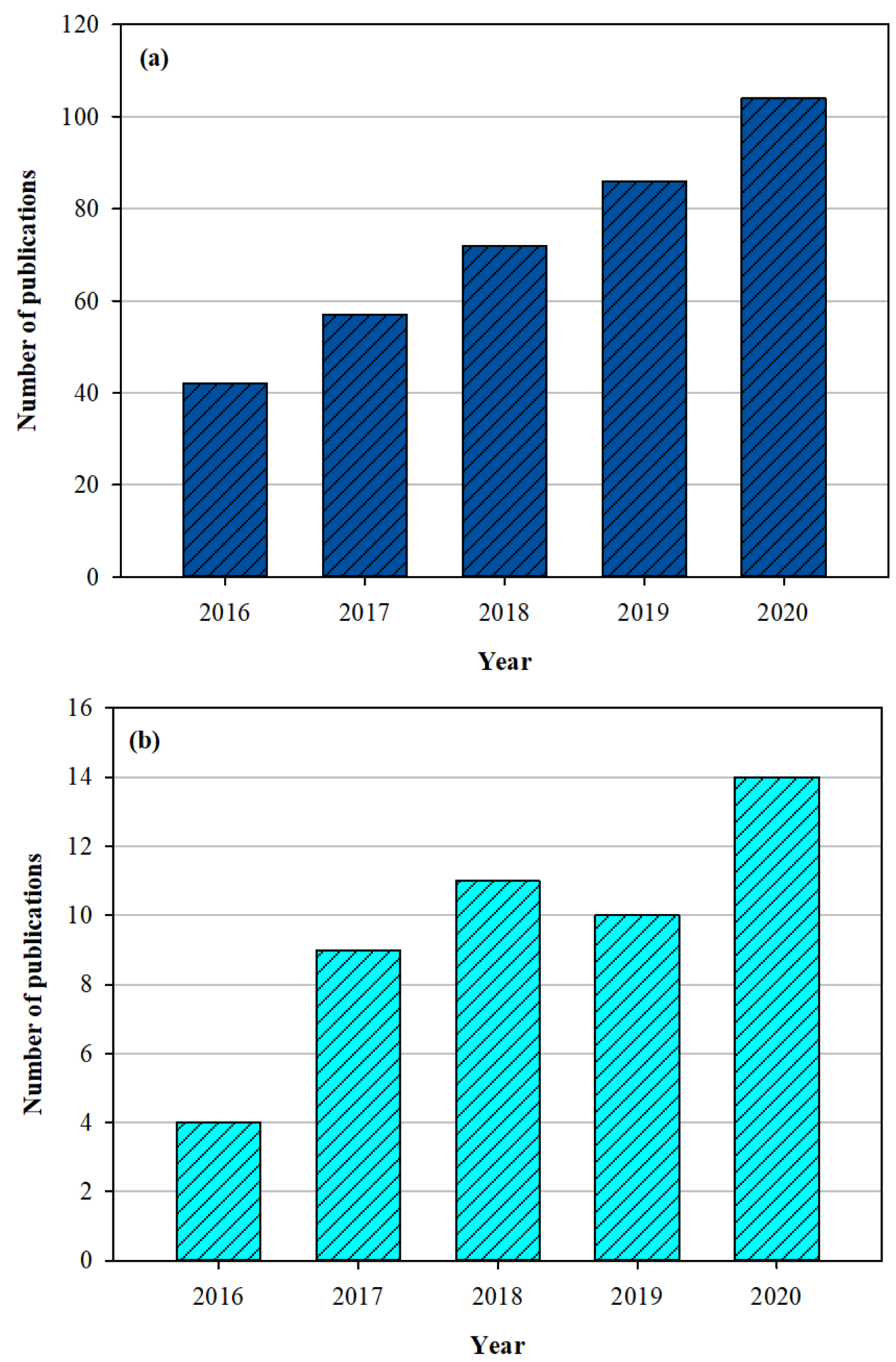

Figure 1. Worldwide production of scientific manuscripts on the dairy industry wastewater treatment fractionated by year (a) and the application of membranes for dairy industry wastewater treatment divided by year (b) from 2016 to 2020 according to the Scopus ${ }^{\circledR}$ database with the following keywords: dairy/wastewater/treatment and dairy/wastewater/treatment/membrane.

The use of treatments applied to the dairy industry wastewater has increased significantly over the years. The largest production of scientific articles occurred in 2020 (104 reports) and more than doubled compared to 5 years ago (42 reports). According to the application of membranes for dairy industry wastewater treatment, the largest report of manuscripts was observed in 2020 (14 reports) and strongly higher when compared to 5 years ago (4 reports). Considering this promising scenario, it is interesting to investigate scientific production worldwide, indicating the regions of substantial application of effluent treatment associated with the dairy industry (Figure 2). 


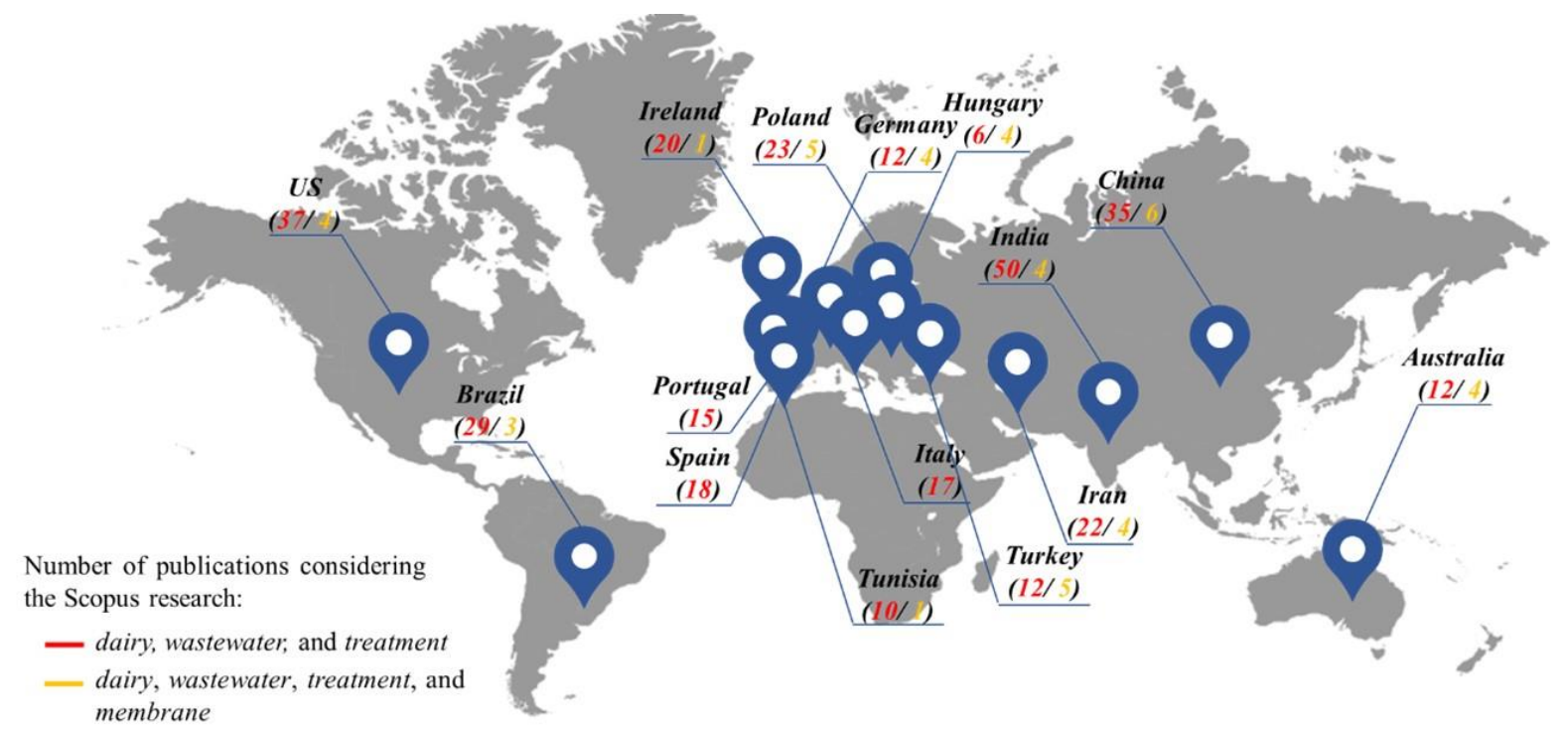

Figure 2. Spatial perspective of the worldwide production of scientific manuscripts on the dairy industry wastewater treatment and the application of membranes for dairy industry wastewater treatment from 2016 to

2020 according to the Scopus ${ }^{\circledR}$ database with the following keywords: dairy/wastewater/treatment and dairy/wastewater/treatment/membrane.

The spatial characterization of scientific production shows the countries that have explored and reported findings on the subject. India, China, US, and Brazil reported several studies on the dairy industry wastewater treatment. This scenario is closely related to the large population of these countries and, consequently, to the high demand for dairy products over the years. In this context, countries like India, Brazil, and China lack adequate infrastructure to treat effluents on a large scale. As a result, the development of studies on this narrative has intensified in recent years. Furthermore, Poland, Iran, Ireland, Spain, and Italy presented promising results regarding exploiting this type of effluent. Many countries in the Middle East, such as Iran, have serious water scarcity problems, mainly due to the region's predominantly desert climate. Thus, the production of studies that aim at alternatives to treat industrial effluents for various purposes is highly expansive [18].

A similar scenario has been widely observed in the European continent over the years since European countries have limited water availability due to the high urban demographic growth and the large amount of water to supply cutting-edge industries and an extremely developed agricultural sector [13]. Overall, the incidence of many European countries as the largest scientific producers regarding the application of wastewater treatment and the use of membranes strategies (Figure 2) is pertinent and indicates the level of innovation that has been adopted in the region recently. Accordingly, the purpose and importance of this review are to provide pertinent information about the application of the membrane separation process in the treatment of wastewater from the dairy industry.

\section{Use of Membranes in Wastewater Treatment}

Membranes can be used at different stages of the production process in the food industry. They can be used to purify raw materials, separate products, or treat effluents generated from industrial activities. The effluent from the dairy industry can consist of milk, whey, detergents, cleaning products in general, production residues, dyes, flavorings, among others. The main objective of using membranes is to separate molecules in suspension or solution by their molecular weight, using different membranes produced with different 
materials. In addition, the membranes have a wide range of pore sizes and can retain molecules of different sizes. For that, it is necessary to know the main objective of applying the membranes to choose the appropriate pore size for the target molecule [19, 20].

If the target molecule is very small and is suspended in a solution containing larger molecules, an integrated membrane system is indicated; that is, the solution must be passed through a larger pore membrane and successively into smaller pore membranes until retention of the target molecule. The type and size of the membrane to be used vary according to the type and size of the contaminant/target molecule retained [21]. In this way, the formation of pie or clogging of the membrane by the larger molecules is avoided, complicating the process and making it necessary to use cleaning protocols every little time, which delays the production process. Severe clogging can shorten the life of the membrane and cause fiber breakage, in the case of hollow fiber membranes, for example. For this reason, primary coagulation treatments, electrocoagulation, advanced oxidative processes, centrifugation and chemical, and biological treatments are often used to remove coarse solids.

In addition to being selective, membranes can be functionalized to meet industry demands. Rahimi et al. [22] studied two antifouling ultrafiltration polyethersulfone membranes to treat synthetic milk processing wastewater prepared with low-cream milk in membrane bioreactors. The authors reported a COD removal efficiency greater than $95 \%$ for membranes prepared with 0.1 wt.\% of $\mathrm{NH}_{2}$ functionalized multiwalled carbon nanotubes and $\mathrm{O}-$ carboxymethyl chitosan modified $\mathrm{Fe}_{3} \mathrm{O}_{4}$ nanoparticles.

\section{Value-Added Products}

Membranes are a physical method of separating two phases, in which the retained phase and/or the permeate phase may be of interest. In the treatment of effluents, the interest is to remove pollutants from the effluent that will later be discarded. However, when the solution to be passed through the membrane has high added value components, as in the case of whey, the part retained in the membrane is of interest. Concentrating the molecules present in the whey can be used in new products to add value and nutrients or be sold separately, generating value for the company. Combined to use all milk components in food products, this action reduces the organic load of the effluents to be discarded, generating environmental and social benefits [23].

Whey is the main pollutant in the treatment of effluents from the dairy industry because of its organic composition (carbohydrates, mainly lactose) and volumetric load [4, 24]. This corroborates the nutritional and biological importance of giving whey an appropriate destination, integrating it into dairy products, such as yogurts, creams, ice creams, pastes, or bakery products, such as cookies and bread, cakes, cookies, among others. Menchik et al. [23] characterized acid whey from Greek-style yogurt and cottage cheese, and milk permeate. The authors reported that the dairy coproducts presented milk solids, such as lactose, protein, and minerals, that can be used in several applications with nutritional benefits.

Gómez et al. [25] performed an assessment via process simulation to produce whey syrups (glucose syrup, and glucose and fructose syrup) and protein concentrate (WPC) attached to a cheese-processing plant. As whey has a high concentration of lactose, lactose hydrolysis can increase the sweetness of the powder and be used as a sweetener in different products or be obtained as sweetener syrups. The authors showed a base case and three other alternatives for obtaining the products and evaluating technical, economic, and environmental aspects. For this purpose, ultra and nanofiltration membranes were evaluated in addition to the use of free 
or immobilized enzymes for hydrolysis. Moreover, the authors also suggest methods of treating the effluent generated after the process, requiring only coagulation with ferric sulfate and anionic polymer and sedimentation for subsequent disposal [25].

When thinking about whey manufacturing in developing countries, many factories do not have enough money to purchase the necessary equipment to produce the powder, such as the spray dryer. Thus, one way to overcome this obstacle is to implement a plant in a consortium with regional companies. Therefore, to reduce the cost of transporting the liquid to be sprayed, an effective strategy is to concentrate the liquid with membranes in order to reduce its volume. In this way, the retained/concentrated membrane can be reused and directed to the generation of value for the regional companies. In addition, as shown in Figure 3, the treated water can still be reused in other industrial processes, such as for cleaning equipment. Figure 4 schematically presents all the possibilities of membrane-based processes in the dairy industry.

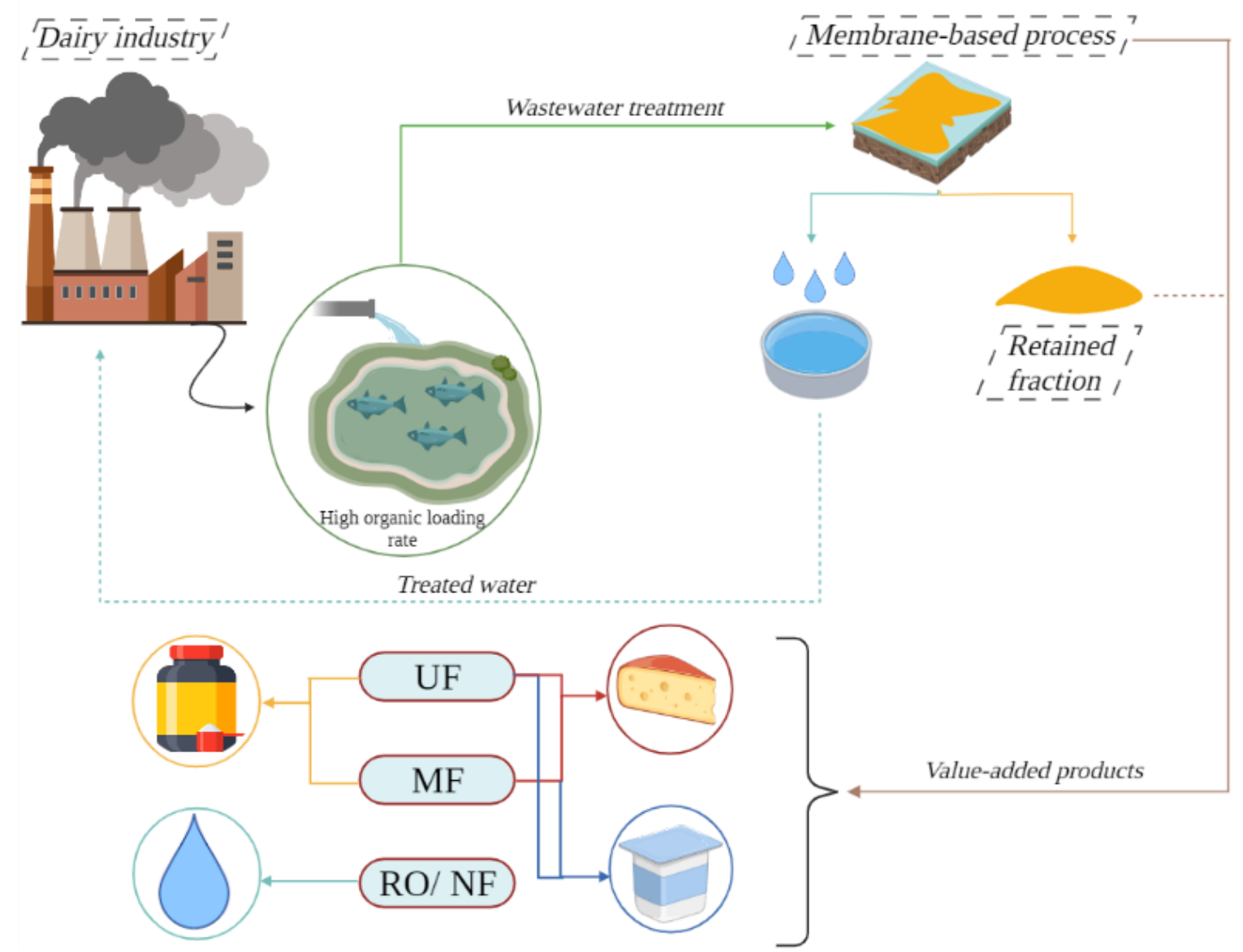

Figure 3. Schematic representation of the process involving the treatment of wastewater from dairy industries with membrane-based processes and the production of value-added products from milk manufacturing procedure. 


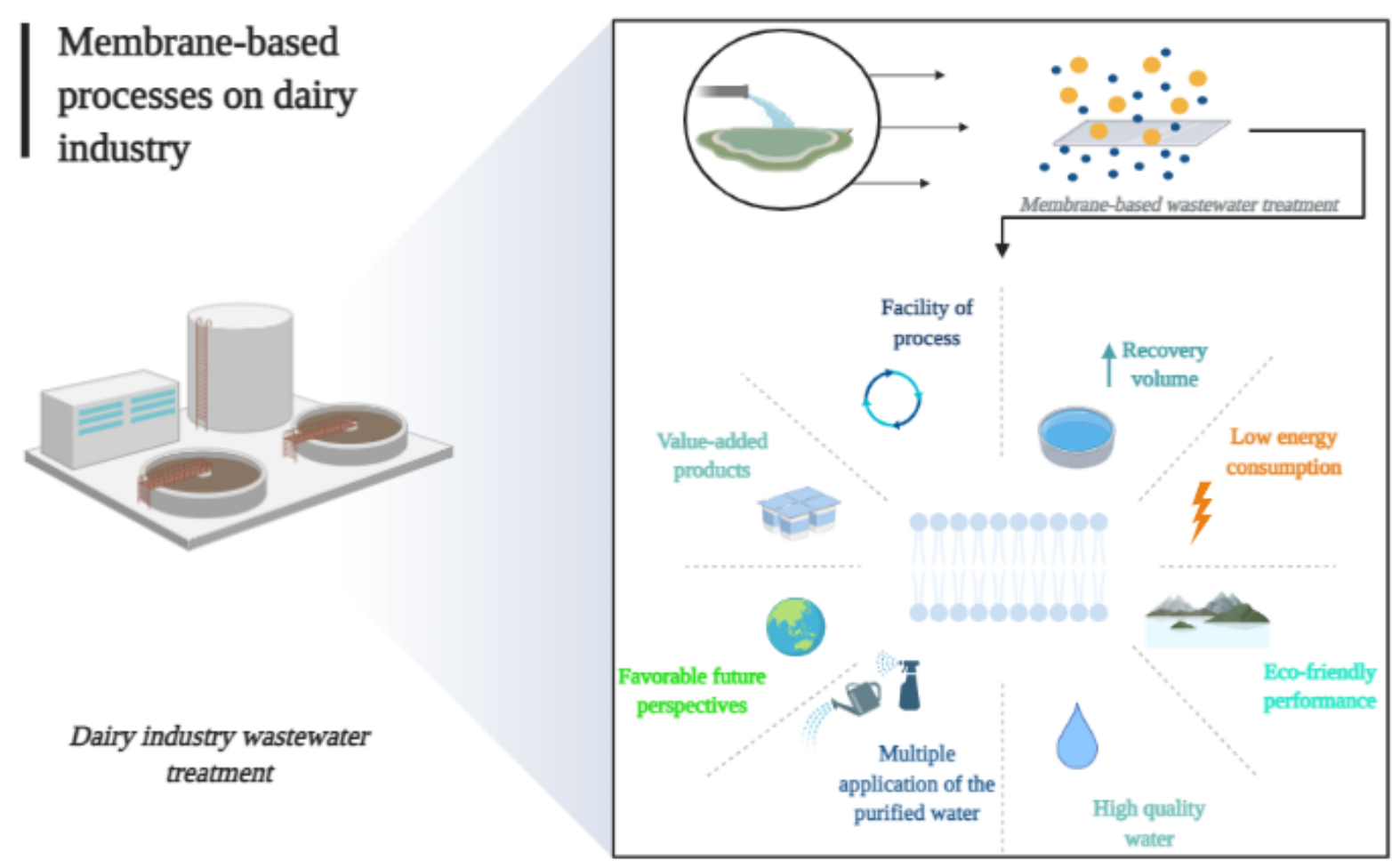

Figure 4. Membrane-based processes in the dairy industry.

Membranes can also separate and isolate compounds of interest from other milk proteins, as in the case of the isolation of the immunoglobulin and lactoferrin fractions [19]. In addition to the interest in proteins, there is also interest in isolating dairy lipid fractions due to their phospholipid content [20]. The highest cost of implementing the membrane system concerns the operational cost. However, the company receives the payback in a short time [26]. This corroborates with the objective of the present article, which was to show ways of using the effluent from the dairy products manufacturing process to add value to products and promote favorable future perspectives.

\section{Conclusions}

The dairy industry effluent consists of molecules with economic and nutritional value that can be used in other processes. Moreover, these molecules can be easily recovered with the use of membranes. This article elucidated alternatives for using the effluent from the dairy industry to generate value in developing countries as well as the main scientific publications.

\section{Funding}

This work was supported by the National Council for Scientific and Technological Development (CNPq) [grant number 308936/2017-5; 428180/2018-3; 306241/2020-0]; Coordination for the Improvement of Higher Education Personnel (CAPES) [grant number 001]; and Research Support Foundation of the State of Rio Grande do Sul (FAPERGS) [grant number 16/2551-0000522-2].

\section{Acknowledgments}

The authors would like to thank the anonymous reviewers for their valuable comments and suggestions to improve the paper's quality. 


\section{Conflicts of Interest}

The authors declare no conflict of interest.

\section{References}

1. Ortez, M.; Bir, C.; Olynk Widmar, N.; Townsend, J. Dairy Product Purchasing in Households with and without Children. JDS Commun. 2021, 2, 7-12, https://doi.org/10.3168/jdsc.2020-19305.

2. Food and Agriculture Organization of the United Nations (FAO). Dairy market review https://www.fao.org/3/cb4230en/cb4230en.pdf (accessed May 19, 2021).

3. Hawkins, J.; Yesuf, G.; Zijlstra, M.; Schoneveld, G. C.; Rufino, M. C. Feeding Efficiency Gains Can Increase the Greenhouse Gas Mitigation Potential of the Tanzanian Dairy Sector. Sci. Rep. 2021, 11, 1-15, https://doi.org/10.1038/s41598-021-83475-8.

4. Slavov, A. K. General Characteristics and Treatment Possibilities of Dairy Wastewater-a Review. Food Technol. Biotechnol. 2017, 55, 14-28, https://doi.org/10.17113/ftb.55.01.17.4520.

5. Ahmad, T.; Aadil, R. M.; Ahmed, H.; Rahman, U. ur; Soares, B. C. V.; Souza, S. L. Q.; Pimentel, T. C.; Scudino, H.; Guimarães, J. T.; Esmerino, E. A.; et al. Treatment and Utilization of Dairy Industrial Waste: A Review. Trends Food Sci. Technol. 2019, 88, 361-372, https://doi.org/10.1016/j.tifs.2019.04.003.

6. Shewa, W. A.; Dagnew, M. Revisiting Chemically Enhanced Primary Treatment of Wastewater: A Review. Sustain. 2020, 12, https://doi.org/10.3390/SU12155928.

7. Ashekuzzaman, S. M.; Forrestal, P.; Richards, K.; Fenton, O. Dairy Industry Derived Wastewater Treatment Sludge: Generation, Type and Characterization of Nutrients and Metals for Agricultural Reuse. J. Clean. Prod. 2019, 230, 1266-1275, https://doi.org/10.1016/j.jclepro.2019.05.025.

8. Flint, S.; Bremer, P.; Brooks, J.; Palmer, J.; Sadiq, F. A.; Seale, B.; Teh, K. H.; Wu, S.; Md Zain, S. N. Bacterial Fouling in Dairy Processing. Int. Dairy J. 2020, 101, 104593, https://doi.org/10.1016/j.idairyj.2019.104593.

9. Nabbou, N.; Benyagoub, E.; Mellouk, A.; Benmoussa, Y. Risk Assessment for Chemical Pollution of Dairy Effluents from a Milk Processing Plant Located in Bechar (Southwest of Algeria). Appl. Water Sci. 2020, 10, 1-12, https://doi.org/10.1007/s13201-020-01309-w.

10. [10] Boguniewicz-Zablocka, J.; Klosok-Bazan, I.; Naddeo, V. Water Quality and Resource Management in the Dairy Industry. Environ. Sci. Pollut. Res. 2019, 26, 1208-1216, https://doi.org/10.1007/s11356-0170608-8.

11. Akansha, J.; Nidheesh, P. V.; Gopinath, A.; Anupama, K. V.; Suresh Kumar, M. Treatment of Dairy Industry Wastewater by Combined Aerated Electrocoagulation and Phytoremediation Process. Chemosphere 2020, 253, 126652, https://doi.org/10.1016/j.chemosphere.2020.126652.

12. Mateus, G. A. P.; Formentini-Schmitt, D. M.; Nishi, L.; Fagundes-Klen, M. R.; Gomes, R. G.; Bergamasco, R. Coagulation/Flocculation with Moringa Oleifera and Membrane Filtration for Dairy Wastewater Treatment. Water. Air. Soil Pollut. 2017, 228, https://doi.org/10.1007/s11270-017-3509-z.

13. Zielińska, M.; Galik, M. Use of Ceramic Membranes in a Membrane Filtration Supported by Coagulation for the Treatment of Dairy Wastewater. Water. Air. Soil Pollut. 2017, 228, https://doi.org/10.1007/s11270-0173365-X.

14. Wang, Y.; Serventi, L. Sustainability of Dairy and Soy Processing: A Review on Wastewater Recycling. J. Clean. Prod. 2019, 237, https://doi.org/10.1016/j.jclepro.2019.117821.

15. Bouchareb, R.; Derbal, K.; Özay, Y.; Bilici, Z.; Dizge, N. Combined Natural/Chemical Coagulation and Membrane Filtration for Wood Processing Wastewater Treatment. J. Water Process Eng. 2020, 37, 101521, https://doi.org/10.1016/j.jwpe.2020.101521.

16. Ezugbe, E. O.; Rathilal, S. Membrane Technologies in Wastewater Treatment: A Review. Membranes (Basel). 2020, 89, https://doi.org/10.3390/membranes10050089.

17. Bortoluzzi, A. C.; Faitão, J. A.; Di Luccio, M.; Dallago, R. M.; Steffens, J.; Zabot, G. L.; Tres, M. V. Dairy Wastewater Treatment Using Integrated Membrane Systems. J. Environ. Chem. Eng. 2017, 5, 4819-4827, https://doi.org/10.1016/j.jece.2017.09.018.

18. Mansoorian, H. J.; Mahvi, A. H.; Jafari, A. J.; Khanjani, N. Evaluation of Dairy Industry Wastewater Treatment and Simultaneous Bioelectricity Generation in a Catalyst-Less and Mediator-Less Membrane Microbial Fuel Cell. J. Saudi Chem. Soc. 2016, 88-100, https://doi.org/10.1016/j.jscs.2014.08.002.

19. Wang, Q.; Chen, G. Q.; Kentish, S. E. Isolation of Lactoferrin and Immunoglobulins from Dairy Whey by an Electrodialysis with Filtration Membrane Process. Sep. Purif. Technol. 2020, 233, 115987, https://doi.org/10.1016/j.seppur.2019.115987.

20. Price, N.; Fei, T.; Clark, S.; Wang, T. Application of Zinc and Calcium Acetate to Precipitate Milk Fat Globule Membrane Components from a Dairy By-Product. J. Dairy Sci. 2020, 103, 1303-1314, https://doi.org/10.3168/jds.2019-16892.

21. Marchesi, C. M.; Paliga, M.; Oro, C. E. D.; Dallago, R. M.; Zin, G.; Di Luccio, M.; Oliveira, J. V.; Tres, M. V. Use of Membranes for the Treatment and Reuse of Water from the Pre-Cooling System of Chicken Carcasses. Environ. Technol. (United Kingdom) 2019, https://doi.org/10.1080/09593330.2019.1624834. 
22. Rahimi, Z.; Zinatizadeh, A. A.; Zinadini, S. Milk Processing Wastewater Treatment in an MBR: A Comparative Study on the Use of Two Synthetic Anti-Fouling PES-UF Membranes. J. Environ. Chem. Eng. 2019, 7, 103369, https://doi.org/10.1016/j.jece.2019.103369.

23. Menchik, P.; Zuber, T.; Zuber, A.; Moraru, C. I. Short Communication: Composition of Coproduct Streams from Dairy Processing: Acid Whey and Milk Permeate. J. Dairy Sci. 2019, 102, 3978-3984, https://doi.org/10.3168/jds.2018-15951.

24. Ahmad, T.; Aadil, R. M.; Ahmed, H.; Rahman, U. ur; Soares, B. C. V.; Souza, S. L. Q.; Pimentel, T. C.; Scudino, H.; Guimarães, J. T.; Esmerino, E. A.; et al. Treatment and Utilization of Dairy Industrial Waste: A Review. Trends Food Sci. Technol. 2019, 88, 361-372, https://doi.org/10.1016/j.tifs.2019.04.003.

25. Gómez, J. A.; Sánchez, Ó. J.; Correa, L. F. Techno-Economic and Environmental Evaluation of Cheesemaking Waste Valorization Through Process Simulation Using SuperPro Designer. Waste and Biomass Valorization 2020, 11, 6025-6045, https://doi.org/10.1007/s12649-019-00833-4.

26. Brião, V. B.; Vieira Salla, A. C.; Miorando, T.; Hemkemeier, M.; Cadore Favaretto, D. P. Water Recovery from Dairy Rinse Water by Reverse Osmosis: Giving Value to Water and Milk Solids. Resour. Conserv. Recycl. 2019, 140, 313-323, https://doi.org/10.1016/j.resconrec.2018.10.007. 